\title{
Effect of laparoscopic surgery on the risk for surgical site infections in colorectal resection: results from the Health Insurance Review \& Assessment Service Database
}

\author{
Sang Hyun An ${ }^{1}$, Mi Kyong Youn², lk Yong Kim ${ }^{1}$ \\ ${ }^{1}$ Department of Surgery, Yonsei University Wonju College of Medicine, Wonju, Korea \\ ${ }^{2}$ The Graduate School, Yonsei University Wonju College of Medicine, Wonju, Korea
}

\begin{abstract}
Purpose: To compare the hospital length of stay (LOS), duration of antibiotic use, medical costs, and incidence of surgical site infection (SSI) between laparoscopic colorectal surgery (Lap-CRS) and open CRS (Open-CRS).

Methods: We retrospectively reviewed data of the Health Insurance Review and Assessment Service Surgical Antibiotic Prophylaxis assessment (7th assessment, 2015); the nationwide data were collected from patients who underwent CRS from September to November 2015 in low volume hospital to the tertiary hospital level in Korea.

Results: All 2,751 patients who underwent elective CRS were assessed. The mean hospital LOS (12.18 days vs. 14.16 days, $P<0.001$ ) and mean postoperative LOS ( 8.21 days vs. 9.46 days, $P<0.001$ ) were shorter in the Lap-CRS group than in the Open-CRS group. The mean duration of antibiotic use was shorter in the Lap-CRS group (2.91 days vs. 3.64 days, $P=0.033$ ). The rate of SSI was lower in the Lap-CRS group, but there was no significant difference between the groups $13.57 \%$ vs. $5.01 \%$, $P=0.133$ ). Among the SSI group, the mean LOS (19.5 days vs. 24.9 days, $P=0.081$ ), duration of antibiotic use (12.62 days vs. 15.46 days, $P=0.097$, and medical costs showed no significant difference between the 2 groups.

Conclusion: Lap-CRS is significantly associated with reduced hospital LOS and the duration of antibiotic use in this study. However, we could not identify significant differences in the incidence of SSI according to the type of surgery. To assess the overall benefits of Lap-CRS, studies including the rate of SSI up to 30 days postoperatively will be needed in the future.

[Ann Surg Treat Res 2020;98(6):315-323]
\end{abstract}

Key Words: Colorectal surgery, Laparoscopy, Length of stay, Medical care costs, Surgical site infection

\section{INTRODUCTION}

Recently, laparoscopy has become the main surgical approach for elective colorectal surgery (CRS). Numerous studies have demonstrated that laparoscopic colorectal surgery (Lap-CRS) has shown favorable short-term outcomes including less analgesic use, earlier resumption of diet, and shorter hospital length of stay (LOS), with equivalent oncologic outcomes compared to open CRS (Open-CRS) [1-5]. In particular, numerous studies have revealed that Lap-CRS is associated with a lower incidence of surgical site infection (SSI) than traditional Open-CRS [6,7].

SSI is the most common healthcare-associated infection and is related to high morbidity, mortality, and higher medical costs. In a study by Kirkland et al. [8], the hospital LOS increased 6.5-10.2 days and the medical costs were estimated to be $\$ 2,000-\$ 4,000$ (United States dollar) higher in the case of SSI. In another study in Korea, the hospital LOS increased 5.2 days and the medical costs were higher by about $\$ 2,150,000$ (Korean won) in the case of SSI [9]. CRS is associated with a high incidence of SSI due to the significant bacterial load involved
Received October 23, 2019, Revised March 3, 2020,

Accepted March 23, 2020

Corresponding Author: Ik Yong Kim

Department of Surgery, Yonsei University Wonju College of Medicine, 20 Ilsan-ro, Wonju 26426, Korea

Tel: +82-33-741-0573, Fax: +82-33-741-0574

E-mail: iykim@yonsei.ac.kr

ORCID: https://orcid.org/0000-0001-6375-2216

\section{Copyright (c) 2020, the Korean Surgical Society}

(c) Annals of Surgical Treatment and Research is an Open Access Journal. All articles are distributed under the terms of the Creative Commons Attribution NonCommercial License (http://creativecommons.org/licenses/by-nc/4.0/) which permits unrestricted non-commercial use, distribution, and reproduction in any medium, provided the original work is properly cited. 
in the organ/space. Indeed, the overall infection rate of CRS is reported to be as high as $26 \%[10,11]$. To reduce the incidence of SSI, there have been various efforts such as preoperative mechanical bowel preparation, the use of proper prophylactic antibiotics, and increasing the use of the laparoscopic procedure $[12,13]$.

To date, several studies have reported that Lap-CRS has favorable short-term outcomes such as a reduction in the incidence of SSI, hospital LOS, and medical costs $[2,4,6,14,15]$. Currently, there have been no studies with a large number of patients in multicenter analyses regarding the relationships between the type of surgery and SSI, hospital LOS, and medical costs in Korea. Since 2007 in Korea, the Health Insurance Review and Assessment Service (HIRA) has assessed the adequacy of the use of prophylactic antibiotics in all types of hospitals in the country for the prevention of SSI and for improving the quality of medical service in their Surgical Antibiotic Prophylaxis (SAP) assessment. Therefore, in this study with the multicenter nationwide data of the HIRA-SAP 7th assessment, we compared the hospital LOS, duration of antibiotic use, medical costs, and the incidence of SSI between laparoscopic and open approaches in patients who underwent CRS. We hypothesized that patients undergoing Lap-CRS would have favorable outcomes in terms of hospital LOS, duration of antibiotic use, hospital costs, and lower rates of SSI compared to those undergoing Open-CRS.

\section{METHODS}

\section{Study design}

This is a population-based retrospective study using the data collected to evaluate the adequacy of the prophylactic antibiotic use in surgery from September to November 2015 in Korea (HIRA-SAP, 2015). We collected data on patients who had undergone CRS across varied environments, from low volume hospitals up to tertiary level hospitals. Patients older than 18 years of age were included in the study. The data were collected on the basis of medical records from 86 institutions that performed a minimum level ( $>10$ cases) of CRS. Because the initial survey was conducted for assessing the adequacy of prophylactic antibiotic use, cases that could cause bias were excluded from the study collection. Accordingly, patients who were transferred from another hospital, patients with an American Society of Anesthesiologists physical status (ASA PS) classification of IV or greater, patients with a fever (body temperature $>38^{\circ} \mathrm{C}$ ) preoperatively (within 24 hours), patients on antibiotics before admission, patients with an antibiotic allergy, and patients who underwent other combined operations at the same time were excluded from this study.

\section{Surgical site infection}

SSI was evaluated through medical records by healthcare workers, according to the definitions of the Centers for Disease Control and Prevention (CDC; 1992). The data were collected by using a questionnaire related to SSI in a web-based system developed by HIRA. The reliability of the data was checked by other investigators and the reliability was confirmed to be $>95 \%$. All superficial, deep, and organ/space infections were considered as SSIs in this study. The following 5 conditions were judged to be SSI: (1) purulent drainage from a superficial or deep incision; (2) organisms isolated from an aseptically obtained culture of fluid or tissue from a superficial or deep incision; (3) at least one of the following signs or symptoms of infection: fever $\left(>38^{\circ} \mathrm{C}\right)$, pain or tenderness, localized swelling, redness, or heat, or a superficial incision deliberately opened by the surgeon and a deep incision spontaneously dehiscing; (4) an abscess or other evidence of infection involving a deep incision found on direct examination, during reoperation, or by histopathologic or radiologic examination; (5) diagnosis of superficial or deep incisional SSI by the surgeon or attending physician.

Although according to the CDC criteria, SSI refers to a wound infection occurring within 30 postoperative days, this study only included SSIs that were identified during the hospitalization because we could not collect data after hospital discharge.

\section{Other variables}

The hospital LOS was defined as the total duration of inhospital days for CRS from the day of hospital admission to the day of discharge. The postoperative LOS was defined as the period from the day of surgery to the day of discharge. The duration of antibiotic use was defined as the sum of the number of days of in-hospital antibiotic use and the number of days of antibiotic use prescribed at discharge. The medical costs were determined by health insurance and medical benefits, including a personal burden. However, in this study, the medical costs not covered by health insurance (nonpayment items) were not included.

\section{Statistical analysis}

All statistical analyses were performed using SAS ver. 7.1 (SAS Institute, Cary, NC USA). Categorical variables were described by frequencies and percentages and were analyzed using chi-squared tests to evaluate the differences in the general characteristics of the study patients according to the type of surgery. Continuous variables were described as means and standard deviations and Wilcoxon rank-sum tests were performed for comparisons of variables such as hospital LOS, duration of antibiotic use, and medical costs between the 2 groups. Logistic regression analysis was used to analyze the 
factors affecting SSI. All P-values were 2-sided and statistically significant differences were defined as those having a P-value $<0.05$. This study was conducted after receiving the approval of the Institutional Review Board of the HIRA for the ethical protection of the study patients.

\section{RESULTS}

\section{Patient enrollment and baseline characteristics}

Of 94,551 patients who underwent elective surgery in Korea between September and November 2015 (by HIRA-SAP

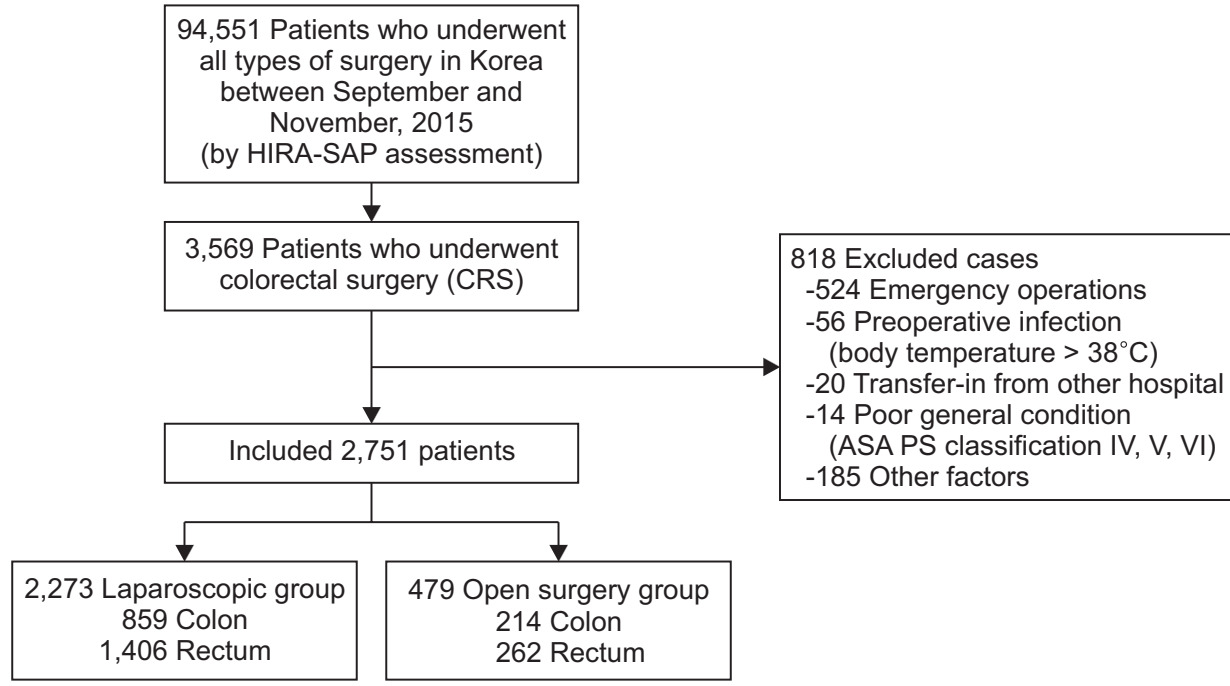

Fig. 1. Flow chart for patient enrollment. HIRA-SAP, Health Insurance Review and Assessment Service Surgical Antibiotic Prophylaxis; ASA PS, American Society of Anesthesiologists physical status.

Table 1. Baseline patient characteristics

\begin{tabular}{|c|c|c|c|c|}
\hline \multirow{2}{*}{ Variable } & \multirow{2}{*}{ Total } & \multicolumn{2}{|c|}{ Type of surgery } & \multirow{2}{*}{ P-value } \\
\hline & & Lap-CRS & Open-CRS & \\
\hline No. of patients & 2,751 & $2,272(82.59)$ & $479(17.41)$ & \\
\hline Sex & & & & 0.238 \\
\hline Male & $1,657(60.23)$ & $1,357(59.73)$ & $300(62.63)$ & \\
\hline Female & $1,094(39.77)$ & $915(40.27)$ & $179(37.38)$ & \\
\hline Mean age (yr) & 63.56 & 63.34 & 64.59 & 0.307 \\
\hline $18-44$ & $197(7.16)$ & $165(7.26)$ & $32(6.68)$ & \\
\hline $45-65$ & $1,206(43.84)$ & $1,009(44.41)$ & $197(41.13)$ & \\
\hline$>65$ & $1,348(49.0)$ & $1,098(48.33)$ & $250(52.19)$ & \\
\hline ASA PS classification & & & & 0.949 \\
\hline I & $575(20.9)$ & $472(20.77)$ & $103(21.50)$ & \\
\hline II & $1,845(60.07)$ & $1,527(67.22)$ & $318(66.39)$ & \\
\hline III & $330(12.0)$ & $272(11.97)$ & $58(12.11)$ & \\
\hline Unknown & $1(0.03)$ & $1(0.04)$ & - & \\
\hline Tumor location & & & & 0.010 \\
\hline Colon & $1,073(39.0)$ & $859(37.81)$ & $214(44.68)$ & \\
\hline Mean operation time & 197.64 & 202.75 & 177.15 & \\
\hline Rectum & $1,668(60.63)$ & $1,406(61.88)$ & $262(54.7)$ & \\
\hline Mean operation time & 180.16 & 179.83 & 181.95 & \\
\hline Prophylactic antibiotics & 2,404 & 2,032 & 372 & $<0.001$ \\
\hline 1st cephalosporin & $331(13.77)$ & $293(14.42)$ & $38(10.21)$ & \\
\hline 2nd cephalosporin & $1,631(67.84)$ & $1,386(67.32)$ & $245(65.86)$ & \\
\hline 3 rd or 4 th cephalosporin & $73(3.04)$ & $58(2.85)$ & $15(4.03)$ & \\
\hline Other & $165(6.86)$ & $112(5.51)$ & $53(14.25)$ & \\
\hline None & $204(8.49)$ & $183(9.01)$ & $21(5.65)$ & \\
\hline
\end{tabular}

Values are presented as number (\%) or unless otherwise indicated.

CRS, colorectal surgery; ASA PS, American Society of Anesthesiologists physical status. 
assessment), the 3,569 patients who underwent major CRS were included in the analysis. Exclusion criteria were emergency surgery, fever, and poor general condition. Finally, a total of 2,751 patients were enrolled in this study (Fig. 1). The patients were categorized into a Lap-CRS group ( $\mathrm{n}=2,272,82.9 \%$ ) and an Open-CRS group ( $\mathrm{n}=479,17.41 \%)$. Of the included patients, $1,657(60.2 \%)$ were men, with a mean age of 63.56 years. There were no significant differences in sex, age, or ASA PS classification between the 2 groups. When classified using the ASA criteria, patients with ASA PS classification II were the most common in each of the groups. Rectal surgery was more commonly conducted in the Lap-CRS group than in the OpenCRS group (61.88\% vs. $54.7 \%, \mathrm{P}=0.010)$. Second-generation cephalosporins were the most commonly used antibiotics for surgical prophylactic purposes (67.84\%) (Table 1).

\section{Comparison between laparoscopic and open approaches}

The mean hospital LOS was significantly shorter in the LapCRS group than in the Open-CRS group (12.18 days vs. 14.16 days, $\mathrm{P}<0.001)$ and the postoperative LOS was also shorter in the Lap-CRS group (8.21 days vs. 9.46 days, $P<0.001$ ). The mean duration of antibiotic use was significantly shorter in the Lap-CRS group than in the Open-CRS group (2.91 days vs. 3.64 days, $P=0.033$ ). The hospital cost was significantly higher in the Lap-CRS group ( $\$ 7,525,000$ vs. $\$ 7,183,000, P<0.001$ ). The mean operation time was significantly longer in the Lap-CRS group than in the Open-CRS group (188.70 minutes vs. 180.02 minutes, $\mathrm{P}<0.001$ ). An SSI was identified in 81 out of 2,272 cases in the Lap-CRS group (3.57\%) and in 24 out of 479 cases in the Open-CRS group (5.01\%). However, this difference did not reach the level of significance $(\mathrm{P}=0.134)$ (Table 2$)$.

\section{Surgical site infection}

In a total of 2,751 cases, there were 105 cases of SSI (3.82\%). The mean hospital LOS, postoperative LOS, and preoperative LOS were longer in the SSI group than in the non-SSI group (mean hospital LOS: 20.72 days vs. 12.91 days, $\mathrm{P}<$ 0.001; postoperative LOS: 14 days vs. 8 days, $\mathrm{P}<0.001$; and preoperative LOS: 3.89 days vs. 2.53 days, $\mathrm{P}=0.004$ ). The mean duration of antibiotic use was longer in the SSI group than in the non-SSI group (13.27 days vs. 2.63 days, $\mathrm{P}<0.001$ ). The medical costs were higher in the SSI group than in the nonSSI group ( $\$ 9,600,000$ vs. $77,300,000, P<0.001$ ). The mean operation time was longer in the SSI group than in the non-SSI group (219 minutes vs. 185 minutes, $\mathrm{P}<0.001$ ) (Table 3).

\section{Factors associated with SSI based on a multivariable logistic regression model}

The factors associated with the development of SSI were

Table 2. Comparison between laparoscopic and open colorectal surgery

\begin{tabular}{|c|c|c|c|c|}
\hline \multirow{2}{*}{ Variable } & \multicolumn{2}{|c|}{ Type of surgery } & \multirow{2}{*}{ Gap } & \multirow{2}{*}{ P-value } \\
\hline & Lap-CRS ( $\mathrm{n}=2,272)$ & Open-CRS ( $\mathrm{n}=479)$ & & \\
\hline Hospital LOS (day) & $12.18 \pm 5.58$ & $14.16 \pm 7.27$ & -1.98 & $<0.001$ \\
\hline Postop hospital LOS & $8.21 \pm 3.78$ & $9.46 \pm 5.50$ & -1.25 & $<0.001$ \\
\hline Preop hospital LOS & $2.48 \pm 2.30$ & $3.05 \pm 3.24$ & -0.57 & $<0.001$ \\
\hline Duration of antibiotics Tx (day) & $2.91 \pm 4.21$ & $3.64 \pm 5.39$ & -0.73 & 0.033 \\
\hline Medical costs (KRW) & $7,525,344$ & $7,183,651$ & 341,693 & $<0.001$ \\
\hline Operation time (min) & $188.70 \pm 117.51$ & $180.02 \pm 130.51$ & 8.68 & $<0.001$ \\
\hline Surgical site infection & $81(3.57)$ & $24(5.01)$ & - & 0.134 \\
\hline
\end{tabular}

Values are presented as mean \pm standard deviation or number (\%).

CRS, colorectal surgery; LOS, length of stay; Postop, postoperative; Preop, preoperative; Tx, treatment; KRW, Korean won.

Table 3. Association between SSI and other variables

\begin{tabular}{lcccc}
\hline \multicolumn{1}{c}{ Variable } & SSI $(\mathrm{n}=105)$ & Non-SSI $(\mathrm{n}=2,646)$ & Gap & P-value \\
\hline Hospital LOS (day) & $20.72 \pm 9.1$ & $12.91 \pm 5.55$ & 7.81 & $<0.001$ \\
Postop hospital LOS & $14.96 \pm 7.22$ & $8.17 \pm 3.76$ & 6.79 & $<0.001$ \\
Preop hospital LOS & $3.89 \pm 3.93$ & $2.53 \pm 2.41$ & 1.36 & $<0.001$ \\
Duration of antibiotics Tx (day) & $13.27 \pm 7.85$ & $2.63 \pm 3.72$ & 10.64 & $<0.001$ \\
Medical costs (KRW) & $9,621,402$ & $7,380,310$ & $2,241,092$ & $<0.001$ \\
Operation time (min) & $219 \pm 104$ & $185 \pm 120$ & 34 & $<0.001$ \\
\hline
\end{tabular}

Values are presented as mean \pm standard deviation.

SSI, surgical site infection; LOS, length of stay; Postop, postoperative; Preop, preoperative; Tx, treatment; KRW, Korean won. 
assessed by logistic regression analysis. The independent risk factors affecting SSI were operation time $(\geq 3$ hours: odds ratio [OR], 2.101; 95\% confidence interval [CI], 1.429-3.112; $\mathrm{P}<0.001$ ) and preoperative hospital LOS ( $\geq 2$ days: OR, 2.010; $95 \% \mathrm{CI}$, 1.347-3.000; $\mathrm{P}<0.001)$. However, the type of surgery, ASA PS classification, age, and tumor location were not independent risk factors for SSI (Table 4).

\section{Comparison between laparoscopic and open approaches in terms of SSI}

Comparing the differences in the hospital LOS and medical costs between the Lap-CRS and Open-CRS groups among patients with SSIs, the mean hospital LOS was shorter in the Lap-CRS group than in the Open-CRS group, but the difference did not reach the level of significance (19.49 days vs. 24.88 days, $P=0.078$ ). The mean duration of antibiotic use was shorter in the Lap-CRS group, but the difference was not significant (12.62 days vs. 15.46 days, $P=0.097$ ). The average medical costs for Lap-CRS were $\$ 9,497,000$ compared to $\$ 10,038,000$ for OpenCRS. Lap-CRS had lower medical costs but the difference did not reach the level of significance $(P=0.936)$.

When all patients were classified into subgroups according to their age and ASA PS classification, however, in elderly patients over 65 years old, the hospital LOS and the mean duration of antibiotic use were significantly shorter with Lap-CRS than with Open-CRS (hospital LOS: 19.0 days vs. 33.3 days, $\mathrm{P}<0.001$; duration of antibiotic use: 11.82 days vs. 21.0 days, $P=0.001$ ).
In addition, among ASA PS classification II patients, who were the most common in the present study, Lap-CRS resulted in a significantly shorter hospital LOS than Open-CRS (19.35 days vs. 26.42 days, $\mathrm{P}=0.014$ ) (Table 5).

\section{DISCUSSION}

The major findings of this study were that patients who underwent Lap-CRS experienced a shorter hospital LOS and a shorter duration of antibiotic use than those who underwent Open-CRS. In addition, this study demonstrated that SSI leads to an increase in the hospital LOS, duration of antibiotic use, and medical costs, in agreement with many previous studies [9]. Although the difference in the incidence of SSI between the 2 groups did not reach the level of significance, the incidence of SSI was lower with Lap-CRS. When we compared the differences between Lap-CRS and Open-CRS only in patients with SSIs, we could not confirm significant differences. However, in a subgroup analysis, Lap-CRS was associated with reduced hospital LOS, especially in the elderly group and the ASA II group.

In the present study, about $82.59 \%$ of CRS $(84.29 \%$ in rectal surgery and $80.05 \%$ in colon surgery) were conducted using a laparoscopic approach during the research period in Korea. This may be explained by the introduction of The Korean Society of Coloproctology's "Korean Laparoscopic Colorectal Surgery Study Group," which was founded in 2000 for disseminating

Table 4. Logistic regression analysis for surgical site infection (SSI)

\begin{tabular}{|c|c|c|c|c|c|c|}
\hline Variable & No. & SSI & Rate (\%) & OR & $95 \% \mathrm{Cl}$ & P-value \\
\hline \multicolumn{7}{|l|}{ Type of surgery } \\
\hline Open & 479 & 24 & 5.01 & Reference & & \\
\hline Lapa & 2,272 & 81 & 3.57 & 0.812 & $0.49-1.379$ & 0.441 \\
\hline \multicolumn{7}{|c|}{ Operation time (hr) } \\
\hline$\leq 3$ & 1,714 & 47 & 2.74 & Reference & & \\
\hline$>3$ & 1,037 & 58 & 5.59 & 2.101 & $1.419-3.112$ & $<0.001$ \\
\hline \multicolumn{7}{|c|}{ Preop hospital LOS (day) } \\
\hline$\leq 2$ & 2,050 & 63 & 3.07 & Reference & & \\
\hline$>2$ & 701 & 42 & 5.99 & 2.01 & $1.347-3.000$ & $<0.001$ \\
\hline \multicolumn{7}{|c|}{ ASA PS classification } \\
\hline I & 575 & 16 & 2.78 & Reference & & \\
\hline II & 1,845 & 72 & 3.9 & 1.418 & $0.818-2.458$ & 0.213 \\
\hline III & 330 & 17 & 5.15 & 1.898 & $0.946-3.808$ & 0.072 \\
\hline \multicolumn{7}{|l|}{ Age (yr) } \\
\hline $18-44$ & 197 & 4 & 2.03 & Reference & & \\
\hline $45-64$ & 1,206 & 43 & 3.57 & 1.748 & $0.633-5.026$ & 0.273 \\
\hline$>65$ & 1,348 & 58 & 4.3 & 2.169 & $0.779-6.042$ & 0.139 \\
\hline \multicolumn{7}{|l|}{ Tumor location } \\
\hline Colon & 1,668 & 63 & 3.78 & Reference & & \\
\hline Rectum & 1,073 & 40 & 3.73 & 0.987 & $0.659-1.477$ & 0.948 \\
\hline
\end{tabular}

OR, odds ratio; $\mathrm{Cl}$, confidence interval; Open, open colorectal surgery; Lapa, laparoscopic colorectal surgery; Preop, preoperative; LOS, length of stay; ASA PS, American Society of Anesthesiologists physical status. 
Table 5. Comparison between Lap-CRS and Open-CRS among the SSI group $(\mathrm{n}=105)$

\begin{tabular}{|c|c|c|c|c|}
\hline Variable & Lap-CRS (n = 81) & Open-CRS $(n=24)$ & Gap & P-value \\
\hline \multicolumn{5}{|l|}{ SSI Group } \\
\hline Hospital LOS (day) & $19.49 \pm 7.98$ & $24.88 \pm 11.40$ & -5.39 & 0.078 \\
\hline Postop hospital LOS (day) & $14.30 \pm 54$ & $16.17 \pm 9.18$ & -1.87 & 0.659 \\
\hline Preop hospital LOS (day) & $3.48 \pm 3.21$ & $5.25 \pm 5.63$ & -1.77 & 0.157 \\
\hline Duration of antibiotics Tx (day) & $12.62 \pm 7.63$ & $15.46 \pm 8.35$ & -2.84 & 0.096 \\
\hline Medical cost (KRW) & $9,497,770$ & $10,038,662$ & $-540,892$ & 0.936 \\
\hline Operation time (min) & $222 \pm 105$ & $206 \pm 102$ & 16 & 0.554 \\
\hline Old age group, $(>65 \mathrm{yr}$ ) with SSI & $48(59.26)$ & $10(41.67)$ & & 0.794 \\
\hline Hospital LOS (day) & $19.0 \pm 7.85$ & $33.3 \pm 8.51$ & -14.3 & $<0.001$ \\
\hline Postop hospital LOS & $14.0 \pm 6.72$ & $21.0 \pm 10.91$ & -7 & 0.021 \\
\hline Preop hospital LOS & $3.63 \pm 3.27$ & $6.2 \pm 7.77$ & -2.57 & 0.847 \\
\hline Duration of antibiotics Tx (day) & $11.92 \pm 7.52$ & $21.0 \pm 8.86$ & -9.08 & 0.001 \\
\hline Medical costs (KRW) & $9,366,424$ & $11,146,760$ & $-1,780,336$ & 0.078 \\
\hline Operation time (min) & $211 \pm 92$ & $195 \pm 79$ & 16 & 0.643 \\
\hline ASA PS II group with SSI & $60(74.07)$ & $12(50.00)$ & & 0.896 \\
\hline Hospital LOS (day) & $19.35 \pm 7.46$ & $26.42 \pm 12.32$ & -7.07 & 0.014 \\
\hline Postop hospital LOS & $14.13 \pm 5.60$ & $19.42 \pm 9.73$ & -5.29 & 0.012 \\
\hline Preop hospital LOS & $3.67 \pm 3.38$ & $4.25 \pm 5.53$ & -0.58 & 0.864 \\
\hline Duration of antibiotics Tx (day) & $12.73 \pm 7.14$ & $16.92 \pm 9.51$ & -4.19 & 0.121 \\
\hline Medical costs (KRW) & $9,564,139$ & $9,209,155$ & 354,984 & 0.623 \\
\hline Operation time (min) & $224 \pm 98$ & $236 \pm 107$ & -12 & 0.706 \\
\hline
\end{tabular}

Values are presented as mean \pm standard deviation or number (\%).

Open, open colorectal surgery; Lapa, laparoscopic colorectal surgery; Preop, preoperative; CRS, colorectal surgery; SSI, surgical site infection; LOS, length of stay; Tx, treatment; KRW, Korean won; ASA PS, American Society of Anesthesiologists physical status.

pertinent information and standardizing surgical techniques. These efforts allowed Korean surgeons to be trained in Lap-CRS through a number of training programs and regular meetings. According to the "Comparison of Open versus laparoscopic surgery for mid and low REctal cancer After Neoadjuvant chemoradiotherapy (COREAN)" trial in Korea, laparoscopic surgery is feasible and results in a better quality of life for patients with rectal cancer who have undergone laparoscopic surgery after neoadjuvant chemoradiotherapy [16]. It is believed that, based on the results of the study, laparoscopic techniques have been encouraged in rectal surgery in Korea. As many other studies have confirmed, the laparoscopic approach has become the mainstay of CRS currently and its utilization has continued to increase $[17,18]$. Several previous reports have demonstrated that the oncologic outcome of Lap-CRS is comparable with that of Open-CRS in colorectal cancer. In the "Medical Research Council Conventional versus Laparoscopic-Assisted Surgery in Colorectal Cancer (MRC CLASICC)" trial, differences were not found between the laparoscopic and open surgical approaches in terms of overall survival, disease-free survival, and local and distant recurrence [1]. In addition, laparoscopic surgery is known to have favorable short-term outcomes such as less analgesic use, earlier resumption of diet, better cosmetic result, shorter hospital LOS, and lower SSI rate than open surgery [2].

Among perioperative morbidities, SSI is the most frequent healthcare-associated infection and is known to be associated with a longer hospital LOS and higher medical costs. The risk factors for SSI are divided into patient-related factors and procedure-related factors. Patient-related factors include high body mass index, comorbidity, perioperative steroid use, cigarette smoking, and previous laparotomy history. Procedure-related factors include prolonged operative time, bacterial contamination, and large incision length according to the operative approach $[7,19,20]$. Prophylactic antibiotics are an important strategy in the prevention of SSI. In Korea, the administration of SAP was recommended via an intravenous route within 1 hour before skin incision. The use of prophylactic antibiotics varies from hospital to hospital and reflects how well hospitals follow the guideline. The adequacy of prophylactic antibiotic use was reported to be $98.6 \%$ in large-volume or tertiary hospitals and $90.7 \%$ in small-volume hospitals. Additionally, the mean duration of antibiotic use was reported to be 2.53 days in the large-volume hospitals and 4.12 days in small-volume hospitals. In addition to the proper application of prophylactic antibiotics, the increased use of laparoscopic surgery has played an important role in reducing SSI. Over the past 2 decades, with the widespread application of LapCRS and with the effort for proper application of prophylactic antibiotics, the incidence of SSI has decreased $(2.7 \%-8.8 \%)[6,10]$. A study by Kagawa et al. [15] demonstrated that the widespread 
use of laparoscopic surgery to treat colon disease may confer protection against SSI. The contributing factors associated with the lower incidence of SSI with laparoscopic surgery are believed to be the smaller surgical incision, decreased tissue trauma, and elimination of mechanical retraction of the abdominal wall [12]. Based on logistic regression analysis in the present study, the factors associated with SSI were operation time longer than 3 hours and preoperative hospital LOS longer than 2 days. There has been controversy about the hypothesis that a long preoperative LOS increases the risk of SSI [2123]. A study by Mujagic et al. [23] reported that preoperative LOS is not associated with SSI. However, several studies have suggested that a long preoperative LOS is a risk factor for SSI $[21,22]$. The reason for this has not been clearly elucidated, but the hospital environment is a known source of bacterial contamination. In addition, older age, poor general condition, and severe comorbidities may cause in-hospital delay. SSI and increased hospital LOS can also result in increased medical costs. Therefore, if clinicians try to prevent SSI, these efforts can also reduce medical costs.

From an economic point of view, the benefits of laparoscopic surgery are controversial. Research by Keller et al. [24] showed that laparoscopy is cost-effective for colorectal cancer surgery, improving both healthcare expenditures and patient outcomes. In their study, the total cost was significantly lower in the LapCRS group than in the Open-CRS group (mean cost: $\$ 17,269$ vs. $\$ 20,552, \mathrm{P}<0.001)$. In addition, Lap-CRS had a significantly shorter hospital LOS, less utilization of intensive care unit care, and lower rates of skilled nursing facility utilization at discharge, all with the potential for substantial cost savings [24,25]. However, a study by Liang et al. [26] showed that a laparoscopic colectomy was more expensive than open surgery (by approximately $\$ 266.39, \mathrm{P}<0.05$ ). They said the reason for the result is the high additional cost of laparoscopic surgical instruments and devices, as well as the longer operative time. Mar et al. [27] assessed the cost-effectiveness of Lap-CRS through quality-adjusted life years (QALYs). According to their analysis, laparoscopy has been found to be more cost-effective because it was associated with more QALYs and lower costs. However, the study showed that laparoscopy could reduce health benefits for elderly patients over 80 years of age [27]. On the other hand, Vignali et al. [28] demonstrated that LapCRS in an older age group ( $>80$ years) is safe and provides the same short-term benefits as for the group of younger-aged patients in terms of a shorter hospital LOS, fewer postoperative complications, and better physical independence at discharge as the younger individuals enjoy. There are conflicting reports regarding the cost-effectiveness of Lap-CRS, which may be due to different health insurance systems in different countries. The results of our study showed that the occurrence of SSI significantly increased medical costs, but the economic benefits of Lap-CRS were not established.

Our study has several limitations. First, the retrospectively collected data were for the evaluation of proper prophylactic antibiotic administration and not focused on the evaluation of SSI or other variables. The incidence of SSI in this study was $3.82 \%$, which was lower than that in other studies, and may indicate that the SSI rate was underestimated. Generally, the diagnosis of SSI is defined as an infection that occurs within 30 days postoperatively according to criteria set by the CDC in 1992 [29]. Strict 30-day follow-up after the operation is important to obtain reliable data on the incidence of SSI [2]. In this study, however, only infections that were identified during the hospitalization were included and any SSIs that occurred after discharge were not identified. Moreover, because the data used in this study were collected on the basis of medical records, there may be problems related to reliability and validity. The reliability of the survey data was confirmed to be more than $95 \%$, but validity could not be verified because the data not recorded in the hospital medical record could not be confirmed. A previous study by Mangram et al. [30] suggested that the risk factors for SSI be divided into patient-related factors and surgical procedure-related factors. However, HIRA does not provide data about patient-related factors such as nutritional status, smoking, and obesity or procedure-related factors such as the condition of the operating room and the surgical technique. Therefore, we were not able to adjust for these variables. Finally, medical costs not covered by health insurance were not included and this could also be considered a limitation of the study. Nevertheless, the current study is important because it included a significant number of patients who underwent CRS at all types of medical institutions in the country where CRS was performed above a minimum level (>10 CRS cases).

In summary, this nationwide population-based cohort study shows that Lap-CRS has favorable short-term outcomes such as a short hospital LOS and a short duration of antibiotic administration. Although it did not show significant benefits in the reduction of SSI and medical costs due to several limitations, the incidence of SSI was lower in the Lap-CRS group. In this context, the socioeconomic effects of laparoscopic surgery can be expected by reducing the LOS, the duration of antibiotic use, and the rate of SSI. If SSI was evaluated for the 30 days after the surgery, we would be able to confirm this socioeconomic effect more clearly. On the other hand, the additional cost of laparoscopic surgery materials is only \#239,000, which has not changed since 2006. Considering the socioeconomic effects of laparoscopic surgery, it would be better to expand and utilize laparoscopic surgery in more fields. In order to do this, proper reimbursement suitable for the current medical environment is necessary. In the near future, if there was a well-designed large-scale prospective study, it would be helpful to confirm the benefits of Lap-CRS in terms of hospital 
LOS, incidence of SSI, and its socioeconomic effects.

\section{ACKNOWLEDGEMENTS}

\section{Fund/Grant Support}

This study was supported by a grant of 2018 Academic Fund the Korean Surgical Society, Republic of Korea (No. KSS20180003).

\section{Conflict of Interest}

No potential conflict of interest relevant to this article was reported.

\section{ORCID iD}

Sang Hyun An: https://orcid.org/0000-0001-7986-778X

Ik Yong Kim: https://orcid.org/0000-0001-6375-2216

\author{
Author Contribution \\ Conceptualization: IYK, SHA \\ Formal Analysis: IYK, SHA \\ Investigation: IYK, MKY \\ Methodology: IYK, MKY \\ Project Administration: MKY \\ Writing - Original Draft: SHA \\ Writing - Review \& Editing: IYK, SHA
}

\section{REFERENCES}

1. Jayne DG, Thorpe HC, Copeland J, Quirke P, Brown JM, Guillou PJ. Five-year followup of the Medical Research Council CLASICC trial of laparoscopically assisted versus open surgery for colorectal cancer. Br J Surg 2010;97:1638-45.

2. Braga M, Vignali A, Gianotti L, Zuliani W, Radaelli G, Gruarin P, et al. Laparoscopic versus open colorectal surgery: a randomized trial on short-term outcome. Ann Surg 2002;236:759-66.

3. Kim IY, Kim BR, Kim YW. The short-term and oncologic outcomes of laparoscopic versus open surgery for T4 colon cancer. Surg Endosc 2016;30:1508-18.

4. Jensen CC, Prasad LM, Abcarian H. Costeffectiveness of laparoscopic vs open resection for colon and rectal cancer. Dis Colon Rectum 2012;55:1017-23.

5. Kim MK, Lee IK, Kang WK, Cho HM, Kye $\mathrm{BH}$, Jalloun HE, et al. Long-term oncologic outcomes of laparoscopic surgery for splenic flexure colon cancer are comparable to conventional open surgery. Ann Surg Treat Res 2017;93:35-42.

6. Poon JT, Law WL, Wong IW, Ching PT, Wong LM, Fan JK, et al. Impact of laparoscopic colorectal resection on surgical site infection. Ann Surg 2009;249: 77-81.

7. Paulson EC, Thompson E, Mahmoud N. Surgical site infection and colorectal surgical procedures: a prospective analysis of risk factors. Surg Infect (Larchmt) 2017;18:520-6.

8. Kirkland KB, Briggs JP, Trivette SL, Wilkinson WE, Sexton DJ. The impact of surgical-site infections in the 1990s: attributable mortality, excess length of hospitalization, and extra costs. Infect Control Hosp Epidemiol 1999;20:725-30.

9. Park ES, Kim KS, Lee WJ, Jang SY, Choi JY, Kim JM. The economical impacts of surgical site infections. Korean J Nosocomial Infect Control 2005;10:57-64.

10. Chida K, Watanabe J, Suwa Y, Suwa H, Momiyama M, Ishibe A, et al. Risk factors for incisional surgical site infection after elective laparoscopic colorectal surgery. Ann Gastroenterol Surg 2019;3:202-8.

11. National Nosocomial Infections Surveillance System. National Nosocomial Infections Surveillance (NNIS) System Report, data summary from January 1992 through June 2004, issued October 2004. Am J Infect Control 2004:32:470-85.

12. Itatsu K, Sugawara G, Kaneoka Y, Kato T, Takeuchi E, Kanai M, et al. Risk factors for incisional surgical site infections in elective surgery for colorectal cancer: focus on intraoperative meticulous wound management. Surg Today 2014:44:1242-52.

13. Ghuman A, Chan T, Karimuddin AA, Brown CJ, Raval MJ, Phang PT. Surgical site infection rates following implementation of a colorectal closure bundle in elective colorectal surgeries. Dis Colon Rectum 2015;58:1078-82.

14. Brathwaite S, Latchana N, Esemuede I, Harzman A, Husain S. Risk factors for surgical site infection in open and laparoscopic hartmann closure: a multivariate analysis. Surg Laparosc Endosc Percutan Tech 2017;27:51-3.

15. Kagawa Y, Yamada D, Yamasaki M, Miyamoto A, Mizushima T, Yamabe K, et al. The association between the increased performance of laparoscopic colon surgery and a reduced risk of surgical site infection. Surg Today 2019;49:474-81.

16. Kang SB, Park JW, Jeong SY, Nam BH, Choi HS, Kim DW, et al. Open versus laparoscopic surgery for mid or low rectal cancer after neoadjuvant chemoradiotherapy (COREAN trial): short-term outcomes of an open-label randomised controlled trial. Lancet Oncol 2010;11:63745.

17. Vallance AE, Keller DS, Hill J, Braun M, Kuryba A, van der Meulen J, et al. Role of emergency laparoscopic colectomy for colorectal cancer: a population-based study in England. Ann Surg 2019;270:1729.

18. Wyles SM, Miskovic D, Ni Z, Darzi AW, Valori RM, Coleman MG, et al. 
Development and implementation of the Structured Training Trainer Assessment Report (STTAR) in the English National Training Programme for laparoscopic colorectal surgery. Surg Endosc 2016;30:993-1003.

19. Konishi T, Watanabe T, Kishimoto J, Nagawa H. Elective colon and rectal surgery differ in risk factors for wound infection: results of prospective surveillance. Ann Surg 2006;244:758-63.

20. Smith RL, Bohl JK, McElearney ST, Friel CM, Barclay MM, Sawyer RG, et al. Wound infection after elective colorectal resection. Ann Surg 2004:239:599-605.

21. Vogel TR, Dombrovskiy VY, Lowry SF. In-hospital delay of elective surgery for high volume procedures: the impact on infectious complications. J Am Coll Surg 2010;211:784-90.

22. Pereira HO, Rezende EM, Couto BR. Length of preoperative hospital stay: a risk factor for reducing surgical infection in femoral fracture cases. Rev Bras Ortop 2015;50:638-46.

23. Mujagic E, Marti WR, Coslovsky M, Soysal SD, Mechera R, von Strauss M, et al. Associations of hospital length of stay with surgical site infections. World J Surg 2018;42:3888-96.

24. Keller DS, Champagne BJ, Reynolds HL Jr, Stein SL, Delaney CP. Cost-effectiveness of laparoscopy in rectal cancer. Dis Colon Rectum 2014:57:564-9.

25. Keller DS, Delaney CP, Hashemi L, Haas EM. A national evaluation of clinical and economic outcomes in open versus laparoscopic colorectal surgery. Surg Endosc 2016;30:4220-8.

26. Liang JT, Shieh MJ, Chen CN, Cheng YM, Chang KJ, Wang SM. Prospective evaluation of laparoscopy-assisted colectomy versus laparotomy with resection for management of complex polyps of the sigmoid colon. World J Surg 2002:26:377-83.
27. Mar J, Anton-Ladislao A, Ibarrondo O, Arrospide A, Lazaro S, Gonzalez N, et al. Cost-effectiveness analysis of laparoscopic versus open surgery in colon cancer. Surg Endosc 2018;32:4912-22.

28. Vignali A, Di Palo S, Tamburini A, Radaelli G, Orsenigo E, Staudacher C. Laparoscopic vs. open colectomies in octogenarians: a case-matched control study. Dis Colon Rectum 2005:48:2070-5.

29. Horan TC, Gaynes RP, Martone WJ, Jarvis WR, Emori TG. CDC definitions of nosocomial surgical site infections, 1992: a modification of CDC definitions of surgical wound infections. Infect Control Hosp Epidemiol 1992;13:606-8.

30. Mangram AJ, Horan TC, Pearson ML, Silver LC, Jarvis WR. Guideline for prevention of surgical site infection, 1999. Hospital Infection Control Practices Advisory Committee. Infect Control Hosp Epidemiol 1999;20:250-78. 